\title{
Effect of Directed Activities Related to Texts on English Skill: Relevance and Adequacy of the Content of Grade XI Students
}

\author{
Abdul Rauf* \\ Muhammad Saeed ${ }^{* *}$
}

\begin{abstract}
The study was aimed to find out the effect of directed activities related to texts (DARTs) on English writing skill: Relevance and adequacy of the contents. An experimental study was conducted through pre-test post-test control group design. A public sector degree college for boys from district Lahore was selected as sample of the study. Sixty students out of 400 enrolled in the session 2018-19 were selected and divided into two equal groups randomly. Study intervention period was of 16 weeks. A supply type test was used to measure students' English writing skill. Test was marked according to the rubrics TEEP (Test of English for Educational Purpose) developed by Reading University UK. Data were analyzed by using repeated measures paired sample t-test and independent sample t-test. Findings revealed that directed activities related to texts (DARTs) had statistically significant positive effect on students' English writing skill. English Teachers for grade XI were recommended to teach English text with the help of DARTs as classroom activities for the development of students' English writing skill. Grade XI students were also recommended to practice DARTs to improve their English writing skill.
\end{abstract}

Keywords: English language, directed activities, writing skill, relevance and adequacy of the content, English as second language.

\footnotetext{
* Ph.D Scholar, IER, University of the Punjab, Email: proffabdulrauf@gmail.com

** Professor, IER, University of the Punjab Email: drsaeed1961@hotmail.com
} 


\section{Introduction}

Language is composed of four skills which are listed as listening, speaking, reading, and writing. Learning each skill is essential to get competency over language (Javed \& Kausar, 2017). Every skill of a language plays important role in language learning. Two of them (listening and reading) are receptive because these are used to get information. Two of them (speaking and writing) are productive or reflective skills because of their use to reflect the ideas and points of view (Khan \& Akhtar, 2017). Writing is an essential skill to communicate effectively. Written communication is significant because it becomes the part of record.

Other than daily social communication, writing is part of official communication also. It is writing which preserves and transmits knowledge and information (Younas, 2018). It facilitates to retrieve it later. No field of life is spare from the significance of writing skill (Shahzad, Ali, \& Saeed, 2016). Writing is defined as putting symbols in graphic forms on certain pattern which conveys intended thoughts and ideas of the writer (Maduabuchi \& Iheanacho, 2016). Content is defined as the selection of words: Lexical and grammatical, adequate and relevant, to convey the thoughts and ideas in writing (Younas, 2018).Writing skill is another major component of language learning. Writing, as literature revealed, is to communicate thoughts, ideas, and concepts by putting alphabetical symbols on the pages. This process of writing symbols on pages requires technical skills. These skills may include the use of relevant and adequate content. Content functions to convey the meaning what writer wants to say. If content is irrelevant the proper meaning cannot be conveyed.

According to Ahmed and BtBidin (2016) content is main element which carries the message. Alshammari (2015) elaborates that content should not be limited to exercises only but it should have the semantic consideration for the place where and when it is being used. Viewpoint, plan, consistency, purpose, and integrity of purpose should be covered in the written text or content (Johnstone, Ashbaugh, \& Warfield, 2002). Relevance in writing is the characteristics of selection and logical organization of content. Students are required to develop relevancy while writing their assignments and attempting examination. The absence of relevance is commented by the examiner in the words that it is irrelevant answer (Yoshimura, 2009). Maduabuchi and Iheanacho (2016) write that such text is commented as it does not answer the question and so on. In simple words, such text having no relevancy in content is said that it does not meet the requirements of reader and is not the answer of the question 
in academic sense. Johnstone, Ashbaugh, and Warfield (2002) have exemplified the relevance in text by saying that prompt and unexpected choice of writer to answer a question is irrelevancy in writing. It, however, expresses knowledge and background information of writer on the topic but information in hand cannot be guessed. Digresses of information from logical sequence develops irrelevancy in writing (Alshammari, 2015). Lengthy and intrusive passages are example of information digresses.

\section{Rationale of the Study}

English as an international language is inevitable for the development and progress in every walk of life. Educational institutions have handed over this responsibility to teachers who are teaching English as second language at different grade levels. English is taught as second language in Pakistan. Second language is learnt rather than acquired. Second language learning becomes easy and effective when it is supported with activities. National Curriculum of English for grade XI (2006) also focused to develop writing skill with the help of different activities because learning writing is essential for students. They may utilize it in their daily as well as official lives for effective communication. Literature suggests various activities which may be effective for teaching English writing skill. Writing skill as recommended by linguistics is linked with reading skill. The activities which engage students with active reading are claimed by linguistics as effective for the development of writing skills. It is also well accepted maxim that good reader is good writer. Lunzer and Gardner (1979) claimed in the book titled "The effective use of reading" that directed activities related to texts encourage reader to read text carefully and go beyond the literal comprehension of the text and think what they read. Present study was designed for the intervention of DARTs in the class for teaching English language text and to find out their effect on students' English writing skill: Relevance and adequacy of the text.

\section{Literature Review}

Directed activities related to texts (DARTs) have been bifurcated into two main categories. These categories are known as reconstruction and analysis activities for teaching English language. Changed and modified text is presented in reconstruction activities. Original text is segmented and broken down into chunk and pieces and given to students to rearrange and construct it again in original form. Students are directed 
to find out the gaps and jumbling in the given text. These types of activities enable the students to perceive the structure of written texts and enable them to read the texts critically (Bitchener, Young, \& Cameron, 2005).

Chuenchaichon (2011) enlisted four reconstruction activities: 1) Text completion-texts are presented to the students by deletion of some phrases or sentences or words. Students are directed to fill the given gap as original by reading it critically and putting words, phrases, or sentences in the gaped place; 2) Diagram completion - students again are given a diagram with deleted labels. They are directed to label the diagram by writing the appropriate words, phrases, or sentences; 3 ) Completion Activities with Disordered Text - texts in jumbled form is predicted and arranged in logical order under this activity. Texts are further categorized in logical relation of concepts and structure; and 4) Prediction: students are required to predict the parts and segments of given texts and assign them proper name according to the use in sentence and parts of speech.

Second category of DARTs is analysis activities. These activities develop analytical skill of learner (Deane, Sheehan, Sabatini, Futagi, \& Kostin, 2006). Students are enabled to analyze texts in different forms. These activities use unmodified original texts. De Morgado (2009) enlists analysis activities as: 1) Underlining and highlighting: This requires finding out specific piece of information and relating it to its logical antecedent. It also enables pupils to select the supporting sentences, phrases, or words of a topic or idea. It develops skimming and scanning ability to read a text. 2) Labeling: Students label texts by giving set of labels as prediction, conclusion, and evidence etc. 3) Segmenting: Given texts are segmented into parts of its logical units of information, or sentence structure. 4) Diagrammatic representation: Texts are represented in the form of diagram. It encourages students to construct a diagram from written texts to make it comprehensive. Diagramming will be in flow, concept, maps, or labeled models etc. 5) Tabular representation: Students read the original texts in critical way and extract information from written texts and present it again in another form of tabulation (Kragler, Walker, \& Martin, 2005).

Writing is an active skill of language (Yoshimura, 2009). It is used as medium of communication by human being. Writing is not a language but complement of speech or spoken language (Tabatabaei, \& Ali, 2012). It is tool of making language be read by another person in absence of speaker. Text is the result of writing. The recipient of writing activity is reader and the motivation behind writing is storytelling, correspondence, publication, and diary writing. 
Academic institutions focus and make writing skill part of their curriculum. This is applied in all majors. The basic objective behind is to train bachelors to become competent writer (Ortega, 2013). Words play pivotal role in every walk of life. Words give meaning to everything. Words enable a person to communicate effectively (Khan, \& Akhtar, 2017). Proper communication is the target of every dialogue. Writing involves intelligence, education, and critical thinking of writer. It is complex skill of language therefore it is pains taking process of putting ideas into the words. The words are arranged into phrases; phrases become sentences; sentences form paragraphs, and paragraphs are known as composition. Ideas are generated in result of extensive reading. Reading comprehension extends writing skills (Ortega, 2013). Writing in no way is easy to practice. It involves intelligence as well as critical thinking. Critical thinking is skill which enables a person to comprehend, apply, analyze, synthesize, and evaluate the observations, or reflections gained from fields of life (Khan, \& Akhtar, 2017).

\section{Theoretical Framework of the Study}

Theoretical framework reflects the review and description of the theories which support the problem and phenomena understudy. It helps researcher to conceptualize the study in broader context or the field of knowledge. Language learning is cognitive process because it is a conscious process along with deliberate application and usage of learning strategies. Strategies are defined as special or particular procedure to process information that improves understanding, retention or learning of such information (Ortega, 2013). Author states that language has been and is cognitive activity because it occurs within the milieu of other cognitive abilities like attention, problem solving, and memory. Various cognitive theories have been propounded for second language acquisition. Such theories focus how second language learners think, understand, and know while learning a language. A cognitive theory considered second language learning as conscious and reasoning process. It focuses on process of language learning rather than content selection.

Chomsky (1986) presented universal grammar theory of language learning. He claimed that people born with facility and knowledge of language learning (it may be first or second language) and he named it language acquisition device (LAD). Author's idea of Universal grammar (UG) states that people already possess language skills without knowing it. Under this theory second language acquisition is focused with respect to users' linguistics competence - what they already know, rather than 
performance - what they actually understand and say (Cain \& Oakhill, 2012).

Piaget's cognitive theory states children's stage by stage language learning. It also reveals the progress and development of their logical thinking and reasoning skills. There are four stages of Piaget's cognitive development theory in reference to language acquisition. Each involves different aspects of language acquisition. These are sensory-motor which is characterized as assimilation, pre-operational that is to accommodate new words with previous mental schema, egocentrism involves animism because children's language becomes egocentric and they see things from their own perspective, and operational period which is divided into two parts - concrete and formal operational periods. At this stage language becomes formal, mature, and logical (McLaughlin, 1987).

According to Ortega (2013) cognitive second language acquisition theories are broadly divided into two spectrums: Traditional information processing which have been dominated SLA theorizing and research since 1980s and emergentism developed in late 1990s out of traditional information processing. Author further states that according to information processing human mind functions as processor which constantly works on what it receives input and gives output in the shape of performance.

Other than these Krashen (1981) presented theory of second language acquisition which is widely known and accepted in the realm of second language acquisition. This theory has five key hypotheses. These state language learning as cognitive function.

The above discussion and review of language learning theories help to decide English writing skill as cognitive activity because it involves cognitive skills. English writing skill may be taught under the supervision of cognitive theories. So, developing English writing skill with the help of directed activities related to text comes under cognitive theories.

\section{Objective and Hypothesis}

The objective of the study was to find out the effect of directed activities related to texts (DARTs) on grade XI students' English writing skill: Relevance and adequacy of the content. To achieve this objective, following null hypothesis was developed.

$\mathbf{H}_{\mathbf{0}}$ : There is no statistically significant difference between experimental and control groups mean scores on English writing skill: Relevance and adequacy of the content of grade XI students. 


\section{Research Methodology}

\section{Sample Selection and Intervention}

An experimental study was carried out through pre-test post-test control group design. A public sector degree college for boys was selected conveniently as a cluster for the selection of sample for the study. Sixty (60) students of grade XI out of 400 enrolled in the session 2018-19 were selected randomly by using random number table. These 60 students were divided into two equal groups having 30 each. One group was selected as experimental by tossing a coin and second as control group.

English textbook I and grammar composition for grade XI published by Punjab Curriculum and Textbook Board (PCTB) was selected as content for intervention. Experimental group was taught the selected content with the help of directed activities related to texts (DARTs). Control group was taught without the help of DARTs but the same content was taught through lecture method, textbook reading method, and grammar translation method. Intervention was period comprised of 16 weeks. There were six classes per week having 45 minutes period per day. On Friday there was 30 minutes period.

\section{Instrument of the Study}

Data were collected with the help of a supply type English writing skill test which was developed by the researchers having 13 questions from English textbook I and English composition for grade XI. It was developed by observing the scientific mechanism i.e. after reviewing English curriculum and textbook. Table of specification was developed to ensure the validity and reliability of the test. English writing skill test was validated by four experts having mastery over English language skill and test development techniques. Two experts were from the field of educational research and assessments while other two were from the field of English language teaching. Experts' valuable suggestions were incorporated in the test. Test was marked according to TEEP (Test of English for Educational Purpose) as rubrics developed and validated by Reading University.

\section{Data Analysis and Interpretation}

In order to analyze the data and test the null hypothesis "There is no statistically significant difference between experimental and control groups mean scores on English writing skill: Relevance and adequacy of 
the content of grade XI students", repeated measures of paired sample ttest and independent sample t-test were applied. Data analysis has been presented in two tables. Table 1 comprises of statistical values gained from repeated measures paired sample t-test. It shows comparison of same group's pre-test and post-test mean score. Table 2 shows the statistical values from independent sample t-test and Cohen's d. Independent sample t-test was used to compare the two independent groups. Pre-test mean score comparison reveals equality of variance for both groups and post-test comparison shows effect sized through Cohen's d value.

Table 1

Pre-test and Post-test Mean Score Comparison of Experimental and Control Groups on English Writing Skill: Relevance and Adequacy of the Content

\begin{tabular}{lccccc}
\hline Groups & Mean & $S D$ & t-value & $d f$ & $\begin{array}{c}\text { Sig. (2- } \\
\text { tailed) }\end{array}$ \\
\hline Experimental group post-test scores & 36.90 & 1.668 & 16.174 & 29 & .000 \\
Experimental group pre-test scores & 29.97 & 1.520 & & & \\
Control group post-test scores & 29.97 & 1.273 & .732 & 29 & .470 \\
Control group pre-test scores & 29.67 & 1.882 & & & \\
\hline
\end{tabular}

Note: $\mathrm{p}=0.05$ and $\mathrm{n}=30$

Table 1 is on repeated measures paired sample t-test statistical results for mean score comparison of experimental and control group on English writing skill: Relevance and adequacy of the content. Statistical values showed that experimental group performed better in post-test (mean $=36.90, \mathrm{SD}=1.668)$ than pre-test $($ mean $=29.97, \mathrm{SD} 1.520)$. Repeated measures paired sample t-test showed statistically significant effect of directed activities related to texts (DARTs) on writing skill: Relevance and adequacy of content $\mathrm{t}(29)=16.174, \mathrm{p}<0.001$.

Whereas pair 2 in table 1 yielded results of pre-test and post-test mean score comparison of control group. It revealed that control group showed miner improvement in post-test (mean $=29.97, \mathrm{SD}=1.273$ ) than pre-test (mean $=29.67, \mathrm{SD}=1.882)$. Repeated measures paired sample ttest showed statistically insignificant effect of Directed activities related to texts (DARTs) on English writing skill: Relevance and adequacy of the content $\mathrm{t}(29)=.732, \mathrm{p}>0.001$. This minor improvement might be predicted as by chance rather than teaching English with the help of textbook method, lecture method, and grammar translation method.

The statistical results failed to support the null hypothesis $\mathrm{H}_{0}$ : "There is no statistically significant difference between experimental and control groups mean scores on English writing skill: Relevance and 
adequacy of the content of grade XI students" and accepted an alternate hypothesis $\mathrm{H}_{\mathrm{A}}$ : "There is statistically significant difference between experimental and control groups mean scores on English writing skill: Relevance and adequacy of the content of grade XI students".

Table 2

Pre-test and Post-test Mean Score Comparison of Two Independent Groups on English Writing Skill: Relevance and Adequacy of the Content

\begin{tabular}{llcccccc}
\hline Test & Groups & Mean & $S D$ & $t$-value & $d f$ & $\begin{array}{c}\text { Sig.(2- } \\
\text { tailed) }\end{array}$ & $d$ \\
\hline Pre-test & Experimental group & 29.97 & 1.520 & .679 & 58 & .500 & \\
& Control group & 29.67 & 1.882 & & & & \\
Post-test & Experimental group & 36.90 & 1.668 & 18.099 & 58 & .000 & .92 \\
& Control group & 29.97 & 1.273 & & & & \\
\hline
\end{tabular}

Note: $\mathrm{p}=0.05$ and $\mathrm{n}=30$

Table 2 showed statistical results gained from independent sample t-test. This was comparison to find out the variance between experimental and control group on the basis of pre-test and post-test mean score comparison of two independent groups. Results revealed that there was statistically insignificant difference of variance on the basis of pre-test mean score comparison between experimental group (mean=29.97, $\mathrm{SD}=1.520$ ) and control group (means=29.67, $\mathrm{SD}=1.882$ ) conditions; $\mathrm{t}(58)=.679, \mathrm{p}>.001$. This indicated that both independent groups, experimental and control, were equal in variance in pre-test scores. So, it was concluded that both groups were equal in terms of scores of pre-test on English writing skill: Relevance and adequacy of the content.

Second comparison in the table 2 was on post-test scores. This comparison of variance was statistically significant between experimental group (mean $=36.90, \mathrm{SD}=1.668)$ and control group (mean=29.97, $\mathrm{SD}=1.273$ ) conditions; $\mathrm{t}(58)=18.099, \mathrm{p}<.001$. This difference was further supported with Cohen's effect size value $(\mathrm{d}=.92)$ which suggested high practical significance between experimental and control groups on post test scores. These results yielded that both groups experimental and control were statistically significantly different in variance of post-test scores. It was concluded that both groups experimental and control gained different scores in post-test on English writing skill: Relevance and adequacy of the content. So, the above statistical results failed to support the null hypothesis $\mathrm{H}_{\mathrm{o}}$ "There is no statistically significant difference between experimental and control groups mean scores on English writing skill: Relevance and adequacy of 
the content of grade XI students" and accepted an alternate hypothesis $\mathrm{H}_{\mathrm{A}}$ : "There is statistically significant difference between experimental and control groups mean scores on English writing skill: Relevance and adequacy of the content of grade XI students".

\section{Results and Discussion}

Current study was conducted to find out the effect of directed activities related to texts (DARTs) on English writing skill: Relevance and adequacy of the content at grade XI in Pakistan. Data analysis revealed that directed activities related to texts (DARTs) were effective for teaching English writing skill: Relevance and adequacy of the content at grade XI. Students outperformed in post-test scores on English writing skill. This finding was also consistent with Tabatabaei and Ali (2012) which was conducted to answer the question whether reading based pre writing activities effect on English as foreign language writing skill at intermediate level. The study was carried out through experimental design. It revealed that various activities selected for teaching English writing skill had positive effect on students' English writing skill.

Study finding that DARTs were effective for teaching English writing skill: Relevance and adequacy of content, was further consistent with the finding of the study conducted by Ahmed and BtBidin (2016). The study was carried through mix-method design: Quantitative and qualitative. Quasi experimental design with pre-test and post-test basis was carried. Results were reported by authors that students showed significant improvement in their post-test scores on English writing skill.

Current study finding is also consistent with Fatima and Pathan (2016) which was aimed to find the vocabulary learning strategies adopted by graduate students and their effect on English writing skill. This study also suggested the effectiveness of vocabulary learning strategies for the development of English writing skill.

The results of Mermelstein (2015) are also consistent with present study findings. Mermelstein (2015) also recommended extensive reading to develop English writing skill. Author has concluded that extensive reading is effective for the development of English writing skill. Javed and Kausar (2017) results support the findings of present study. Authors conducted an experimental study to develop students' English writing skill. The study results revealed statistical significant effect of activities on students' English writing skill. This study was conducted in Pakistani context.

Present study findings are also consistent with Din and Ghani (2018) which was conducted at intermediate level grade XI and XII to 
find out the answer of the question that weather reading literature enhances students' English lexical competency. The authors recommended that literature reading enhanced English lexical competency of students at intermediate level. They also recommended the reading literature for teaching English lexical competency.

\section{Conclusion and Recommendations}

Current study findings conclude that directed activities related to texts (DARTs) are effective for teaching English writing skill: Relevance and adequacy of the content. There is visible difference between pre-test and post-test mean scores of experimental group on English writing skill (see table 1 and 2). Students outperformed in post-test scores. Control group, on the other hand, showed statistically insignificant difference between pre-test and post-test mean scores on English writing skill in reference to relevance and adequacy in the content.

On the basis of findings English teachers of grade XI are recommended to use DARTs as classroom activities for teaching English writing skill: Relevance and adequacy of the content. Students of grade XI learning English as second language in Pakistan are also recommended to use DARTs as activities to develop their English writing skill for effective communication. 


\section{References}

Ahmed, R. Z., \& BtBidin, S. J. (2016). The effect of task based language teaching on writing skills of EFL learners in Malaysia. Open Journal of Modern Linguistics, 6(3), 207-218.

Alshammari, M. M. (2015). New developments in teaching reading comprehension skills to EFL learners. International Journal of English Language Teaching, 3(1), 1-10.

Bitchener, J., Young, S., \& Cameron, D. (2005). The effect of different types of corrective feedback on ESL student writing. Journal of Second Language writing, 14(3), 191-205.

Chomsky, N. (1986). Knowledge of language: Its nature, origin, and use. Preager Publisher. Retrieved from https://books.google.com/books?hl=en\&lr=\&id=b0VZPtZDL8kC\&o $\mathrm{i}=$ fnd\&pg=PR11\&dq=Chomsky+(1986)\&ots=kdmh4BS93a\&sig=3k vsQE2zWLT2NwPlHfB6Z4uZfIg

Chuenchaichon, Y. (2011). Impact of intensive reading on the written performance of content textbooks. The Reading Teacher, 59(3), 254261.

Cooper, A., \& Bikowski, D. (2007). Writing at the graduate level: What tasks do professors actually require? Journal of English for Academic Purposes, 6(3), 206-221.

De Morgado, N. F. (2009). Extensive reading: Students' performance and perception. Reading: Pearson Education.

Deane, P., Sheehan, K. M., Sabatini, J., Futagi, Y., \& Kostin, I. (2006). Differences in text structure and its implications for assessment of struggling readers. Scientific Studies of Reading, 10(3), 257-275.

Din, M., \& Ghani, M. (2018). Developing lexical competence through literature: A study of intermediate students of Pakistan. International Journal of English Linguistics, 8(4), 164-173.

Fatima, I., \& Pathan, Z. H. (2016). Investigating learning strategies for vocabulary development: A comparative study of two universities of Quetta, Pakistan. Advances in Language and Literary Studies, 7(2), 7-12.

Government of Pakistan (2006). National curriculum of English for class XI-XII. Islamabad:Ministry of Education, Curriculum Wing. 
Javed, S., \& Kausar, G. (2017). Applying construction grammar approach in teaching writing skills: An experimental study. Journal of Research in Social Sciences, 5(1), 103-115.

Johnstone, K. M., Ashbaugh, H., \& Warfield, T. D. (2002). Effects of repeated practice and contextual-writing experiences on college students' writing skills. Journal of Educational Psychology, 94(2), 305-315.

Khan, A., \& Akhtar, M. (2017). Investigating the effectiveness of cooperative learning method on teaching of English grammar. Bulletin of Education and Research, 39(1), 1-16.

Kragler, S., Walker, C. A., \& Martin, L. E. (2005). Strategy instruction in primary content textbooks. The Reading Teacher, 59(3), 254-261.

Krashen, S. D. (1981). Second language acquisition and second language learning. University of Southern California.

Lunzer, E., \& Gardner, K. (1979). The effective use of reading.Retrieved from https://eric.ed.gov/?id=ED174979.

Maduabuchi, D. C. H., \& Iheanacho, K. A. (2016). Use of drills and secondary school students' achievement in the English language spelling. Modern Journal of Language Teaching Methods, 6(1), 306315.

Mermelstein, A. D. (2015). Improving EFL learners' writing through enhanced extensive reading. Reading in a Foreign Language, 27(2), 182-190.

Ortega, L. (2013). Understanding second language acquisition. Routledge.

Shahzad, S., Ali, R., \& Saeed, S. (2016). The effects of teachers' lexical competency on students learning outcomes. Journal of Research in Social Sciences, 4(2), 91-105.

Tabatabaei, O., \& Ali, H. A. (2012). The effect of reading-based prewriting activities on the writing performance in an EFL setting. Journal of Educational and Social Research, 2(3), 371-382.

Yoshimura, F. (2009). Effects of connecting reading and writing and a checklist to guide the reading process on EFL learners' learning about English writing. Procedia-Social and Behavioral Sciences, 1(1), 1871-1883. 
Younas, M. (2018). The effectiveness of scaffolding in learning punctuation for primary level EFL students: Action Research in Pakistan. Journal of Research in Social Sciences, 4(2), 12-20.

Citation of this Article:

Rauf, A., \& Saeed, M. (2020). Effect of directed activities related to text on English writing skill: Relevance and adequacy of the content of grade XI students. Pakistan Journal of Education, 37 (2), 47-60. 